\title{
A RARE SALISH BLANKET
}

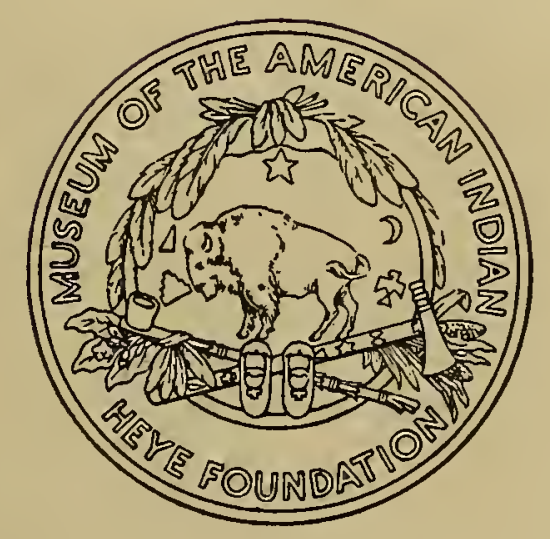

LEAFLETS OF THE

MUSEUM OF THE AMERICAN INDIAN HEYE FOUNDATION

NEW YORK

NUMBER $5, \quad, \quad, \quad$ MARCH 22, 1926 



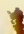

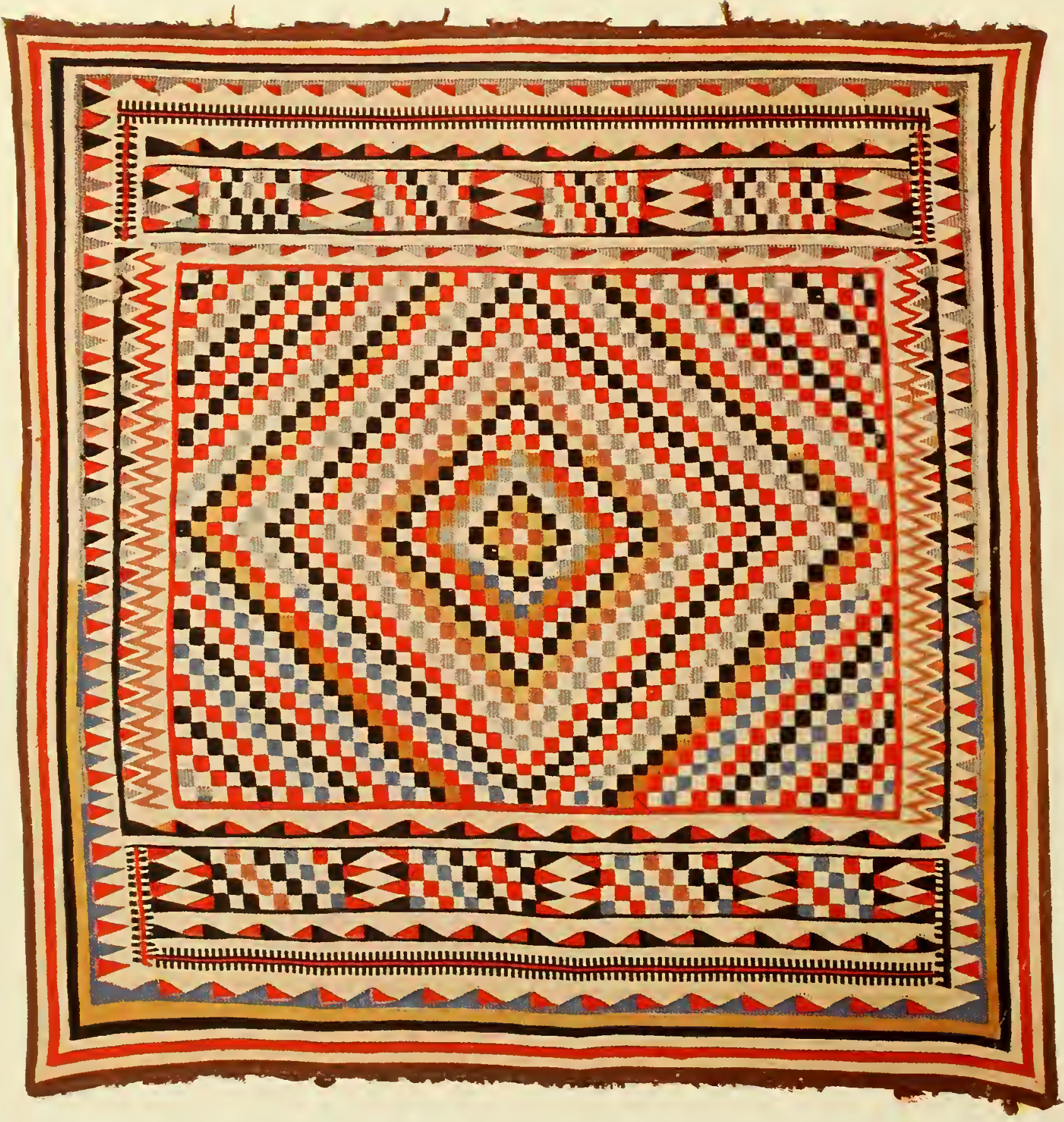

WOVEN BLANKET OF THE SALISH 


\section{A RARE SALISH BLANKET}

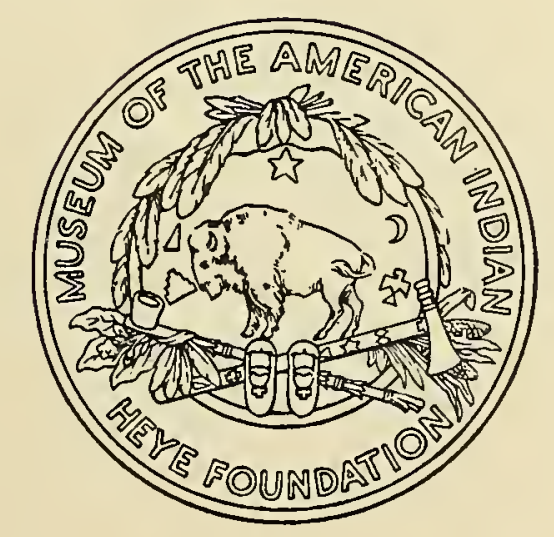

LEAFLETS OF THE

MUSEUM OF THE AMERICAN INDIAN HEYE FOUNDATION, , NEW YORK NUMBER $5, \quad, \quad$ MARCH 22, 1926 
<smiles>C1=C[C@H]2CC[C@H]1C2</smiles> 
THE DIRECTOR AND THE BOARD OF TRUSTEES OF THE MUSEUM OF THE AMERICAN INDIAN, HEYE FOUNDATION, APPRECIATIVE OF THE INTEREST THAT HE HAS EVER MANIFESTED IN ITS ENDEAVORS, AND IN COMMEMORATION OF HIS EIGHTIETH ANNIVERSARY, PUBLISH AND DEDICATE THIS DESCRIPTION OF ONE OF THE MANY TREASURES THAT HAVE COME INTO THE POSSESSION OF THE MUSEUM THROUGH THE GENEROSITY OF

\section{HARMON WASHINGTON HENDRICKS}

NEW YORK, MARCH 22, I926 



\section{A Rare Salish Blanket}

HROUGH the generosity of Mr. Harmon W. Hendricks, the Museum of the American Indian, Heye Foundation, has recently acquired a fine example of the type of blanket that probably contains dog's hair in the materials of which it is woven, from the Salish Indians of British Columbia. Originally obtained about the middle of the last century by Joe Mackay, an old Hudson's Bay Company factor, from the chief of the Tsakuam band of Cowichan Salish at Yale (Shilekuatl), on the lower Fraser river, the blanket was acquired by Lieutenant George T. Emmons, U. S. N., retired, while visiting Victoria during the summer of 1925.

The size of the textile is three feet eight and one-half inches by three feet ten and one-half inches, and it is of the design and color shown in the frontispiece. Blankets of this kind are so rare that very little has been written in regard to them, but a promised publication by the late Dr. C. F. Newcombe and James Teit, with the collaboration of Miss Mary Lois Kissell, will doubtless make known all available information respecting this phase of aboriginal American weaving.

On the general subject Willoughby ${ }^{1}$ says:

"Blankets of goat wool or of dog fleece were in use from the Columbia River, where they are recorded by Lewis and Clark, to the Chilkat in Alaska. In certain sections of the southern region the hair of the dog, and perhaps of other animals, and the down of birds were also used, either with or without the addition of goat wool. The dog was of a woolly haired variety extensively bred for its white fleece, from which was woven a considerable part of the clothing of the people of the Puget sound region and adjacent territory. The fleece was removed from the live animal, probably with shell knives. Vancouver, doubtless the first European to come in contact with the Puget sound tribes, thus describes this animal. ${ }^{2}$ 'The dogs belonging to this tribe of Indians were numerous, and much resembled those of Pomerania,

\footnotetext{
${ }^{1}$ Charles C. Willoughby, A New Type of Ceremonial Blanket from the Northwest Coast, American Anthropologist, N. s., vol. I2, no. I, Jan.-Mar. I9IO.

${ }^{2}$ Vancouver's Discovery of Puget Sound, Meany reprint, p. 136.
} 


\section{A RARE SALISH BLANKET}

though in general somewhat larger. They were all shorn as close to the skin as sheep are in England; and so compact were their fleeces that large portions could be lifted up by a corner without causing any separation. They were composed of a mixture of a coarse kind of wool, with very fine, long hair, capable of being spun into yarn. This gave me reason to believe that their woolen clothing might in part be composed of this material mixed with a finer kind of wool from some other animal, as their garments were all too fine to be manufactured from the coarse coating of the dog alone. The abundance of these garments among the few people we met with, indicates the animal from whence the raw material is procured to be very common in this neighborhood; but as they have no one domesticated excepting the dog, their supply of wool for their clothing can only be obtained by hunting the wild creature that produces it; of which we could not obtain the least information.'

"On another occasion he writes of meeting about 200 Indians, 'some in canoes with their families, others walking along the shore attended by about 40 dogs in a drove, shorn close to their skin like sheep." "

An illustration of descendants of the species of dog referred to is presented in our plate II, from a portion of a photograph reproduced in the Annual Report of the Smithsonian Institution for 1924, and now used by the courtesy of the United States National Museum. In the title of the plate it is stated that this kind of dog has become extinct.

In addition to the example herein illustrated, the only blankets in which dog hair has been employed in conjunction with mountain goat wool or other material, so far as the writer is aware, are two in the National Museum at Washington, one in the Peabody Museum at Cambridge, another in the Provincial Museum at Victoria, and one in the possession of a family in British Columbia. There are therefore only six specimens of this distinctive kind of Indian textile that have been noted, although in Vancouver's time, no doubt, such blankets were at least fairly numerous.

George G. Heye

${ }^{1}$ Vancouver, ibid., p. I62. 


\section{Technique of the Salish Blanket}

OO far nothing has been published on the art of weaving the so0 called dog-hair blankets by the Salish Indians, hence little in regard to methods and implements can yet be presented. The following description of the technique of the weaving of the blanket now in the Museum is the result of an analytical examination of the inception and progress of the weaving elements.

The process throughout is of the kind known as plain twined weaving. Two elements form the weft, which are made to twist in half-turns on each other between the warp strands, one element passing over, the other under, the warp. Fig. I shows the positions of the doubled weft elements in their relation to the warp strands, and the half-turns made between the warp. This class of weaving has been commonly employed by the American Indians in basketry making, as well as in the manufacture

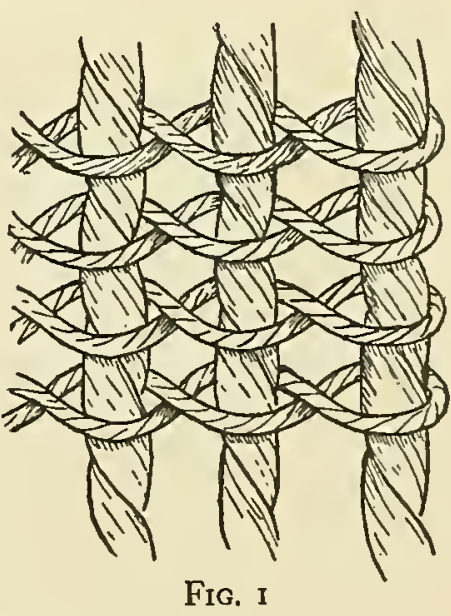

FIG. I of softer fabrics for clothing, bags, and various other articles.

The warp strands of the Salish blanket are composed of eight finely spun threads of uncolored wool twisted together in pairs and finally twisted in to a single cord which forms a warp element about an eighth of an inch or more in diameter. The difference in the size of the warp and the weft results in the unusual ribbed effect, which in appearance is somewhat like the surface of coiled basketry. The weft strands consist of only two threads twisted together.

The frontispiece shows a narrow brown border, the weft of which is composed of five threads at the top and bottom, while at the sides each weft strand consists of only three threads. In designating the top and bottom of the weave, we assume that the blanket was fabricated on a two-bar loom such as is shown in plate $\mathrm{I}, a$, which illustrates a loom procured for the Museum by the late Dr. C. F. Newcombe from the Koksilah, a Salish band living between Nanoose bay and 


\section{A RARE SALISH BLANKET}

Saanich inlet on the southeastern coast of Vancouver island, and on the mainland in the valley of the lower Fraser river nearly as far as Spuzzum, British Columbia. A painting by Paul Kane in 1846 shows such a loom in operation, but, lacking specific information, our description of the technique will be based on the assumption that a loom of the same general type was used. The spinning of the yarn has been described in detail ${ }^{1}$ other than that nothing has been recorded in regard to the process of weaving such an old type of blanket as the one now under discussion. Kane's painting clearly shows the warp in a continuous cord wrapped around the two bars, the proper tension being effected by wedges driven in to the apertures in the sideposts or supports, below the upper and above the lower bar, thus forcing them apart and stretching the warp strands taut. The weaving apparently proceeded from the top downward until the space between the two bars was filled, when, for convenience in working, the finished portion was moved up and over the bar. The removal of the wedges freed the bars so that a rolling process would shift the position of the finished fabric and expose more warp for additional weaving. The wedges were then driven in place as before.

The Museum blanket is bordered with six narrow lines colored in the following order, commencing at the outer edge: brown, white, red, white, black, and, for the upper half, white, and tan-color for the lower half of the last or sixth line. The lines on the upper and lower edges cross the warp and are simply a plain twined weave. The side lines, however, instead of being across the warp, are lengthwise; that is, they follow the same direction as the warp, each color covering three of the warp elements. This necessitated a change in manipulation of the weft. Each line is woven independently of the next one; that is, the weft is carried across the three warp strands in one direction, and is then turned back in the opposite direction.

Between the lines of color a system of interlocking the stitches is introduced, one series looping through those adjoining, and at the same time passing through the warp, as shown in fig. 2. This pro-

\footnotetext{
${ }^{1}$ Mary Lois Kissell, A New Type of Spinning in North America, American Anthropologist, s. s., vol. 18, no. 2, April-June, IgI6. A reproduction of Kane's illustration accompanies Miss Kissell's article.
} 

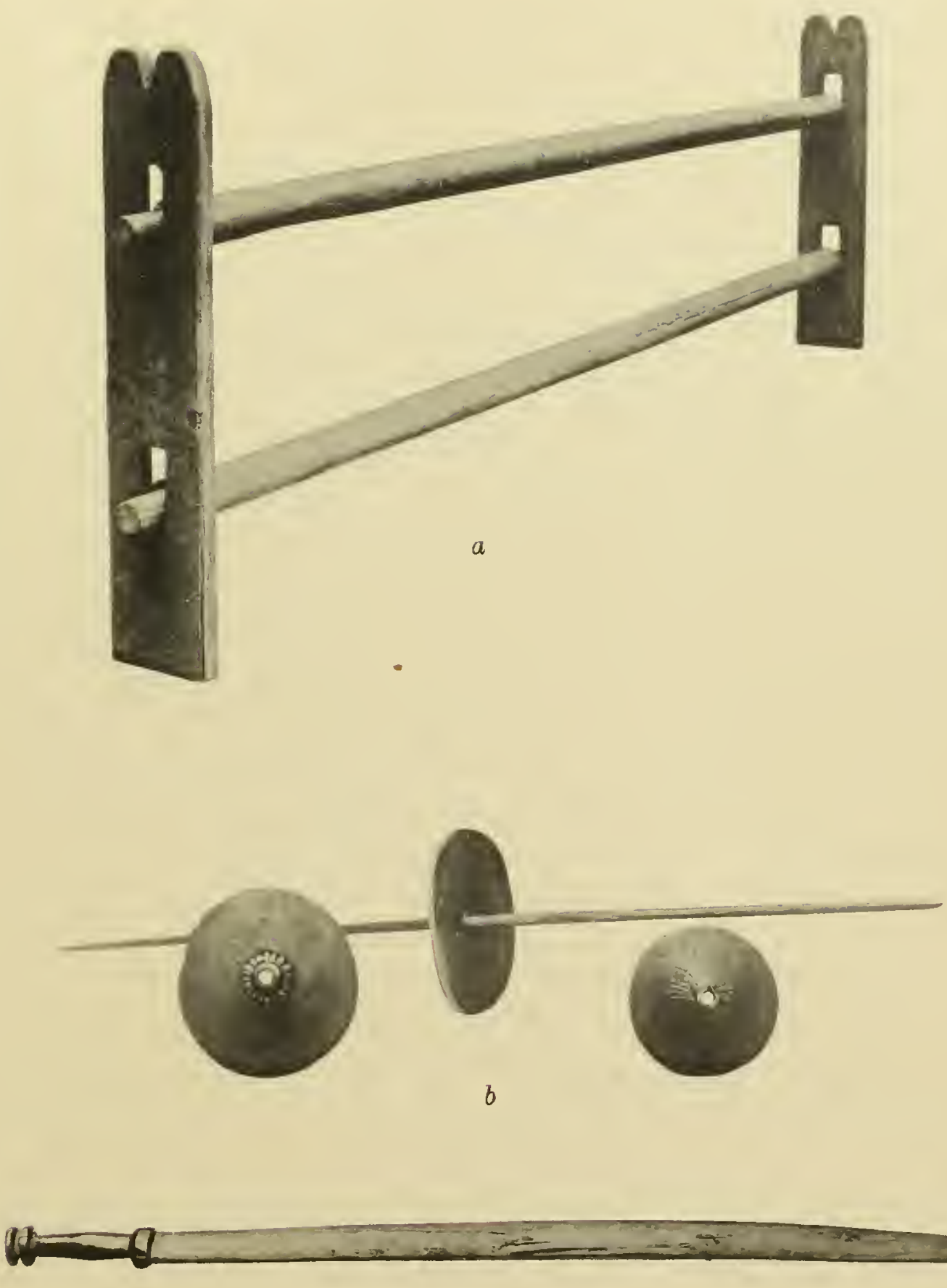

$c$

$a$-TWO-BAR LOOM FROM THE KOKSILAH OF VANCOUVER ISLAND. $b-S P I N D L E$ AND SPINDLE-WHORLS OF THE SALISH OF VANCOUVER ISLAND. c-WOOL-BEATER OF THE SALISH OF VANCOUVER ISLAND

(Length of loom bars, $13 \mathrm{ft}$; diameter of the largest whorl, 9 in.) 



\section{A RARE SALISH BLANKET}

cess produced a firm bonding of the weave. It is possible that a needle of some kind was used for passing the threads through the warp strands: an awl would not seem to be suited to such flexible material. In consequence of this variation in the technique, the side lines are not so sharp and well defined as those along the top and bottom edges. The same difference is readily noticeable in a toothed pattern woven across the warp near the upper and lower edges, and for a space of about six inches lengthwise of the warp. The line woven across is composed of continuous twined threads, one black, the other white, in alter-

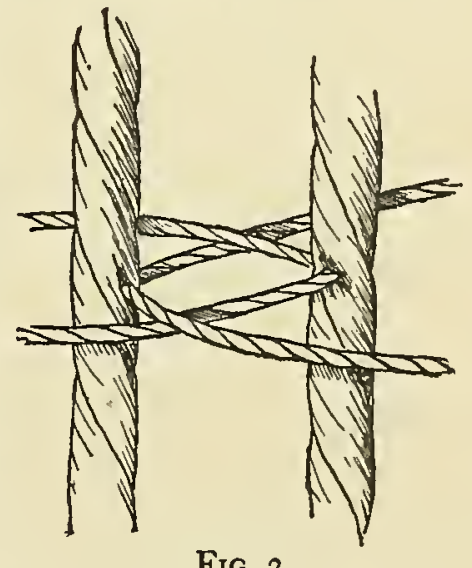

FIG. 2 nating positions as they traverse the weave (fig. 3). By this method what are white spaces on the front of the textile are black on the reverse. This part of the design is remarkably sharp and well executed, while in strong contrast the short portions of what was intended to be the same design lengthwise of the warp are ragged and irregular, in some measure due to the manipulation of the weft as in the case of the side lines in the border. It may be seen in the lower right-hand corner, where this design has been woven lengthwise, that the teeth have been omitted on one side of the bar, which was due probably

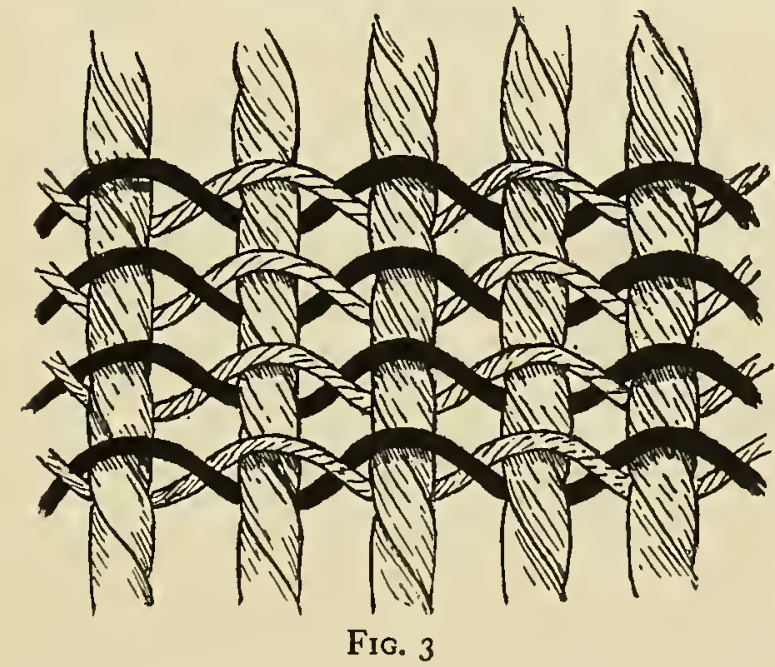
to miscalculation in spacing the squares and triangles in the panel between the two side pieces and tooth design. In consequence, insufficient space was provided for the completion of the pattern. The same reason probably accounts for the discrepancy in the width of the tan-colored line in the lower left-hand corner of the blanket. A series of triangles and zigzag lines, skilfully woven with well-defined, clear-cut edges, appears on each side of the blanket. 


\section{A RARE SALISH BLANKET}

The trend of the stitches would seem to indicate that the outlines of the colored triangles were woven first and the filling afterward; then the white background between the triangles was woven. The tension of the weft in this part of the weave has given the lines of weaving a more or less wavy appearance. The tendency was to draw the warp strands, both the colored and the white, toward the bases of the triangles. This method of inserting the weft at other than right angles to the warp has been observed in some Peruvian textiles. ${ }^{1}$ A small manta from Peru, recently added to the Museum collections as a gift by $\mathrm{Mr}$. Hendricks, is an excellent example of this skilful insertion of angular designs. Two of the red triangles of the Salish blanket, one on each side and near the top of the fabric, have been outlined with a black border in a single line of weaving. The zigzag lines are woven with a series of continuous threads passing from one point to another. Some of the lines, however, show a slight discrepancy in the number of weft crossings to the line, some having four, others six or more; hence this part of the design, where so woven, is somewhat uneven in appearance. In all parts of the textile where the pattern has not been woven directly across, small separations may be seen by transmitted light where the weft has not been caught in to the nearest warp strand. Some of these may have been accidental, others undoubtedly were intentional, somewhat after the manner of certain Peruvian and Oriental lace-like weaves. The apices of the triangles and the points of the zigzag lines all show such treatment, and a like effect has been produced between the series of semicircular patterns at each end of the blanket. The semicircles are on a base line of the same color as a half of the semicircle; the other half is red. The separations occur where the narrowest points of the design come together.

The central panel of the blanket is a checkerboard design with the various colors woven across diagonally. The weave has followed the colors, the weft passing from one square to the other of the same color.

The warp strands at each end of the fabric have been cut off close, and at some time in the past have been covered with a binding of com-

${ }^{1}$ M. D. C. Crawford, Peruvian Textiles, Anthropological Papers of the American Museum of Natural History, vol. xII, pt. 5, p. I20. 


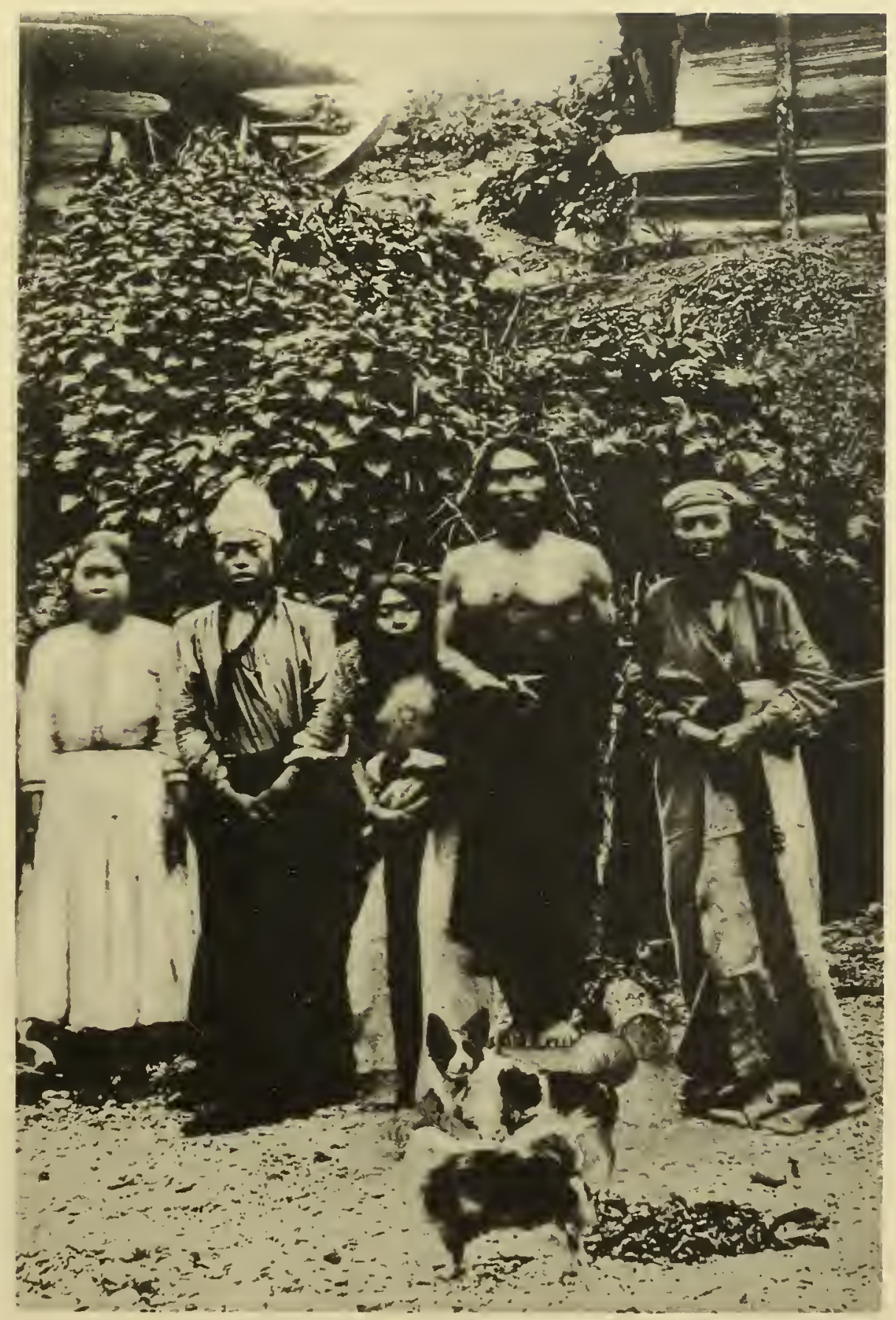

GROUP OF SALISH INDIANS WITH THEIR DOGS (Courtesy of the United States National Museum) 



\section{A RARE SALISH BLANKET}

mercial material which has almost disappeared from use. This binding, probably designed to prevent raveling, may have been applied at the time the weaving of the blanket was finished; but there is no evidence of a bonding of the weave along the edges, which would have been necessary had the warp been left long enough to form a fringe. Time evidently has had no effect on the blanket itself, attesting to the skilful weaving and the excellent wearing qualities of the materials of which it is made.

This blanket has been known for many years, and always has been spoken of as woven of dog-hair; indeed all such are commonly designated "dog-hair blankets" regardless of the use also of other materials in their manufacture. To arrive at a more definite conclusion, a superficial microscopic examination of particles of the weft and warp elements has been made, with the result that the warp was found to be of mountain-goat wool, seemingly without admixture of dog-hair. This determination, however, is not definitive, as only very small fragments were taken for examination, lest the textile suffer injury. A more thorough examination might reveal the use of some dog-hair, but the probability is that goat-wool, being a coarser and more uneven fiber, was used for the concealed warp, and the finer, even hair of the dog employed for the exposed weft. A number of strands of the weft were examined and proved to be of the finer material.

A comparison was made with some hair kindly furnished by the American Museum of Natural History, New York, from the skin of a dog of about the same build and general appearance, which came from Sitka, Alaska. The hair from the blanket in the Museum of the American Indian, Heye Foundation, and the Sitka dog-hair are almost identical. Compared with sheep-wool, there is a decided difference, so that we are at least reasonably safe in assuming that the weft of our blanket is of dog-hair, and the warp of mountain-goat wool. Our identification of the warp fiber as goat-wool has been aided greatly by the studies of James Teit, who has contributed so much to our knowledge of the ethnology of the Salish of British Columbia.

Plate II illustrates the group of Salish with two dogs in the foreground to which attention has already been drawn. Although indistinct, the 


\section{A RARE SALISH BLANKET}

photograph is sufficiently clear to show that the dog was not of a large breed. Kane's picture illustrates a white dog, while the dogs in our illustration are apparently black and white. Judging by the size of the animal it is evident that many shearings would have been necessary to provide sufficient material for weaving a blanket.

The colors of our blanket are suggestive of native dyes, excepting the red, which is rather brilliant for a vegetal dye of British Columbia origin; but information on the native dye materials of that region is lacking.

Other examples of this weave occur in a number of tump-lines, or carrying straps, collected from the Salish of several localities near Tacoma and Olympia, Washington. The warp strands of one specimen are made of a coarse, stiff fiber, closely resembling that obtained from yucca. In other specimens a softer fiber has been used, probably one of the so-called Indian hemps, combined with some commercial cotton yarn. The woven parts of the tump-lines are nine warp strands wide, or about two inches. A straight-line pattern is made by the use of a doubled weft of two colors, one passing over, the other under, the warp, as illustrated in fig. 3. The weft is a native yarn, and the material closely resembles sheep-wool rather than dog-hair.

Of interest in connection with native weaving on the Northwest Coast, we present an illustration of a Salish loom (plate $\mathrm{I}, a$ ), as well as some spindle-whorls and a sword-like implement $(b, c)$ used in beating wool or hair for the purpose of reducing its matted condition preparatory to spinning. The spindles are of special interest because of the size of the whorls and the length of the shafts. The largest whorl is eight inches in diameter and the shaft four feet long.

Two ornate whorls (plate III) were collected from the Nanaimo, a Salish band residing on the eastern coast of Vancouver island and the adjacent mainland of British Columbia. The larger of these, which by an interesting coincidence was a gift to the Museum by Miss Edith Hendricks, sister of Mr. Harmon W. Hendricks, is nine and threequarters inches in diameter.

Vancouver mentions the use of the down of birds in connection with mountain-goat wool and the hair of other animals for weaving. In- 


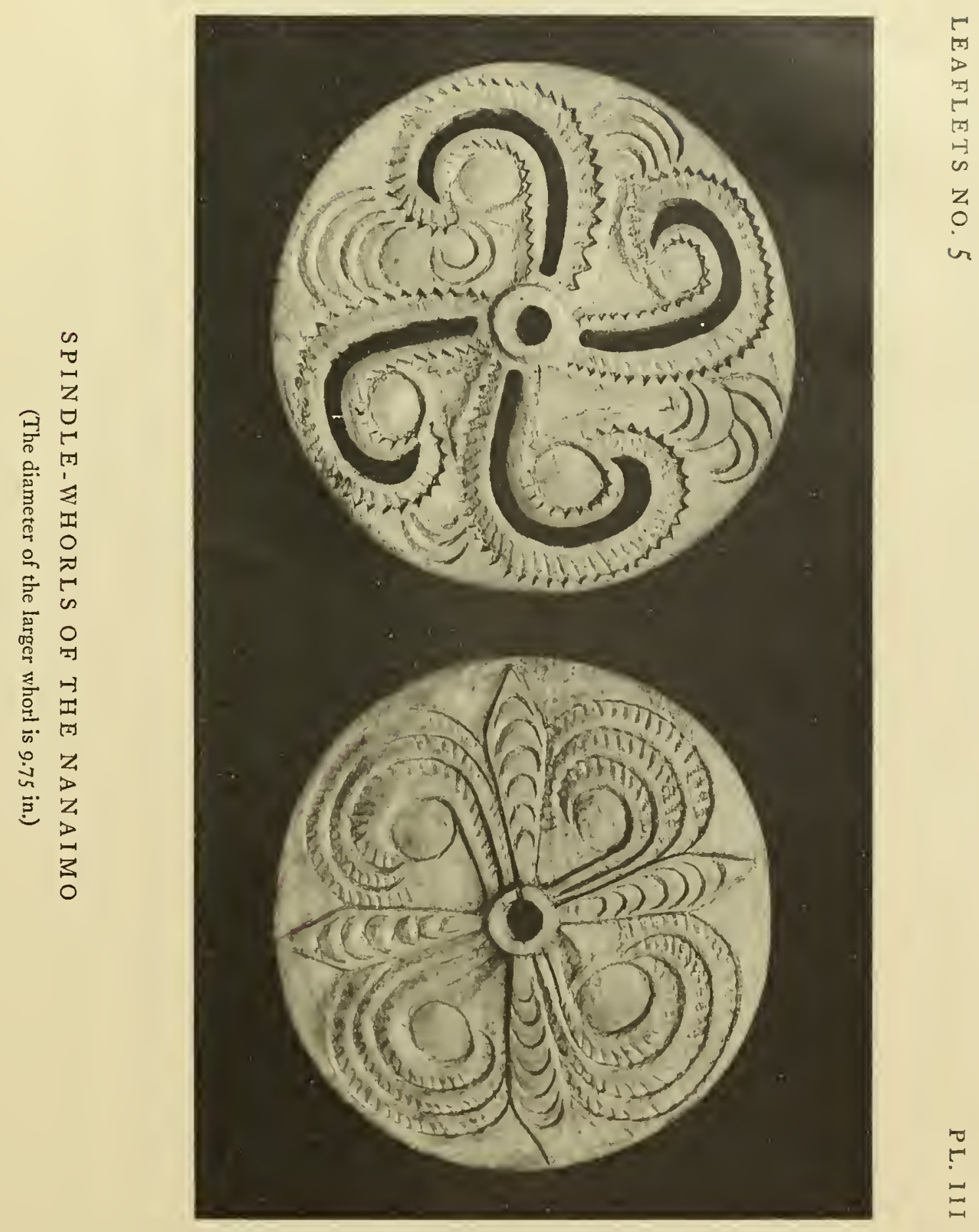





\section{A RARE SALISH BLANKET}

teresting in this connection is a blanket procured for the Museum by James Teit from the Salish of the Fraser River region in 1907. This textile is about three feet square (exclusive of the fringe, which varies in length from six to nine inches) and is made of mountain-goat wool, small downy feathers, and an unidentified milkweed fiber.

The warp and weft are of the same size and materials, a roughly spun cord of about a quarter of an inch in diameter. The feathers are held firmly in the twisted yarn, but the milkweed fiber is in small masses just as it was taken from the seed-pod, no attempt having been made to draw the fibers out so that they might be spun into yarn. This fiber affords no strength; it is easily separated from the wool and feathers, and may have been incorporated in the textile with a view of ornamentation.

The weave of this blanket is a variety of twilled technique, the same as employed in basketry. The weft crosses the warp over-two, underone, over-two, under-one, and so on across the weave. At the edge the weft is turned back and woven across in the opposite direction, leaving a loop at the edge rather than being drawn taut. The order of crossing the warp is changed as each line is woven, that is, it is stepped along one warp, but the system of over-two, under-one, is observed throughout the weave. The diagram (fig. 4) shows the relation of one line to the other regarding the change. This process has produced a series of surface lines crossing the blanket diagonally. The upper and lower edges show the same method of looping the warp as was employed for the turning of the weft.

These loops are bonded with a doubled string of closely spun goat-wool

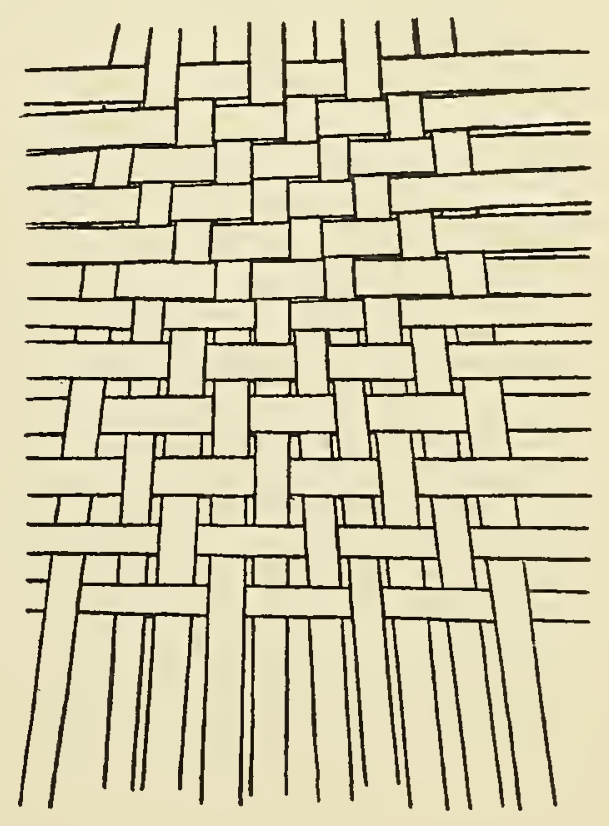

Frg. 4 twined between the loops, as shown in fig. 5. The bonding string is drawn tight over the soft, loosely spun warp, and is not easily 


\section{A RARE SALISH BLANKET}

pulled off and over the loops. The side and lower edges are finished

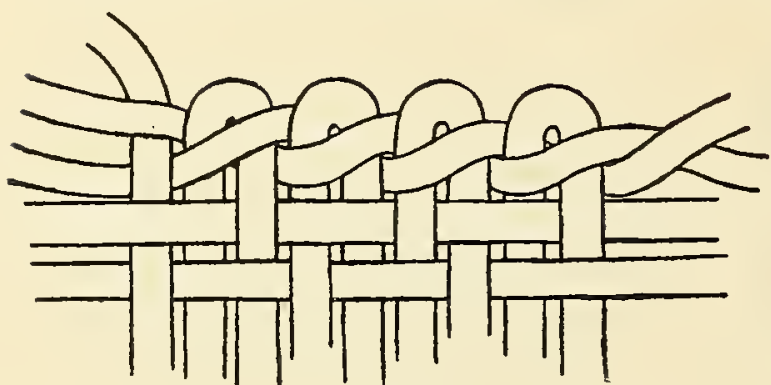

FIg. 5

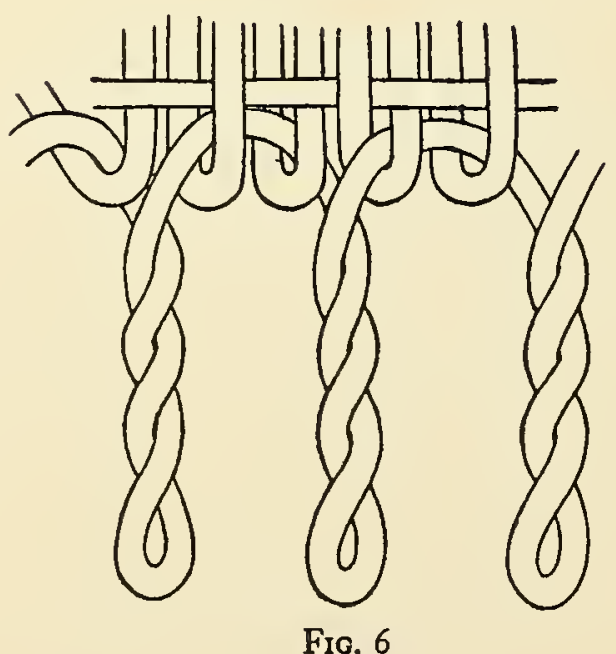

Two other goat-wool blankets, both from the Fraser River region, are in the collections of the Museum, but are without the feather and milkweed fiber mixture. One is of the same variety of twilled weaving as the feathered blanket; the other exhibits a variety in which the crossings are all over-two and under-two (fig. 7), producing a slightly different surface pattern. Both blankets have been bonded and supplied with fringe along their lower edges, as shown in figs. 5 and 6 . They are of about the same size, six feet ten inches by three feet ten inches, exclusive of the fringe, which in one case is fourteen inches and in the other eighteen inches in length. 
A RARE SALISH BLANKET

For decorative purposes narrow strips of coarsely woven red woolen material have been threaded across the weave at intervals of six or eight inches to eighteen inches or more apart.

William C. Orchard 

SMITSONIAN INSTITUTION LIGRAAIES

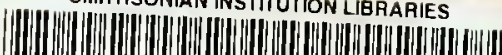

I...

39088011514015 